\title{
EL VINO DE COCOS EN LA NUEVA ESPAÑA. HISTORIA DE UNA TRANSCULTURACIÓN EN EL SIGLO XVII
}

Paulina Machuca, Zamora (Michoacán), El Colegio de Michoacán, 2018, 392 págs.

¿Estamos ante un libro de historia natural, como parece sugerir su encabezamiento? ¿O es tal vez una publicación de carácter cultural? ¿O quizás lo sea de historia del consumo por las múltiples gráficas y cuadros estadísticos que figuran en sus páginas? ¿ $\mathrm{O}$ acaso de historia social por los agentes que inspiraron el relato? Hay que responder afirmativamente a todas estas cuestiones anteriores tanto por separado como sobre todo en su conjunto, porque el libro que el lector tiene en sus manos es todo eso y mucho más. Se trata de un estudio que parte de la investigación de los orígenes y desarrollo de un producto singular, el «vino de cocos» —llamado también «de tuba», en la Nueva España y que en realidad constituye un aguardiente de elevada graduación-, similar al mexcal y procedente de las islas Filipinas, que entra de lleno en el proceso de trasvase cultural entre ambos territorios imperiales. Examina a fondo las características de sus protagonistas, los entonces denominados «indios chinos», incide en el mundo de la producción y de la comercialización hacia mercados urbanos y mineros, con su repercusión en las economías locales, analiza la regulación adoptada por parte de las autoridades coloniales (y consecuentemente afecta a su tributación), pero tampoco olvida los aspectos tecnológicos y el know-how que hicieron posible la mencionada transculturación.

El paisaje natural a lo largo de la costa del Pacífico entre Acapulco y Colima, en México, está aún hoy tapizado de una flora en la que predomina sin duda el árbol que conocemos con el nombre de cocotero (cocos nucifera). Sin embargo, no se trata de una especie autóctona sino de una planta que llegó por el océano, tras un prolongado navegar, desde sus márgenes asiáticos. Explicar esta singularidad en toda su complejidad constituye así el objetivo principal del libro que tenemos entre manos. Su autora, Paulina Machuca, es doctora en Ciencias sociales por el CIESAS mexicano, especializada en historia de los intercambios culturales entre México y Filipinas y profesora e investigadora en el Colegio de Michoacán. Para la realización de este libro hubo de consultar fuentes locales (Colima, Morelia, Acapulco, Guadalajara, entre otras), archivos mineros (Zacatecas, San Luis Potosí), españoles (Archivo General de Indias, Real academia de la Historia) y sobre todo obtener información oral en las islas Filipinas, donde existe una tradición de consumo de 
una bebida que en la banda americana del Pacífico se ha perdido ya, probablemente porque su producción desembocó en la elaboración del conocido mexcal, de menor complejidad en su ejecución.

La publicación que comentamos se segmenta en tres partes bien diferenciadas. La primera, «De la palma al destilado», desgrana en distintos capítulos algunas de las cuestiones que se han mencionado más arriba. En el que inaugura la sección, se estudian los orígenes asiáticos de la palma de coco y su difusión. La autora irrumpe así en una polémica que aún no conoce final. Durante años se había discutido sobre si la semilla del cocotero se habría propagado a través de determinadas corrientes marítimas a la Polinesia — soporta la elevada salinidad del mar- y de allí a Centroamérica antes de la llegada de los españoles o bien lo había hecho a través de una vía africana a partir de Cabo Verde, Puerto Rico y de allí a la costa del Pacífico. En todo caso, ambas vías están apoyadas en argumentos de peso. Sin embargo, la autora opta por presentar algunos documentos históricos que acreditan que la palmera alcanzó las costas mexicanas por dos vías singulares y compatibles entre sí. En primer lugar, la asiático-melanésica, con la participación fundamental del viaje de Álvaro de Mendaña en 1569 y que aun hoy mantienen en su memoria los naturales de Colima, desde donde se difundió hacia el norte y sur de la costa; pero también la vía de los primitivos galeones, que trasladarían la semilla a Acapulco y de allí se habría difundido siguiendo el litoral hacia el norte, donde se emplearía como alimento (aceite, miel, vinagre), medicina y sobre todo bebida, unos usos similares a los acostumbrados en las islas Filipinas en donde todavía se mantiene esta práctica.

La reflexión anterior conduce a la autora a preguntarse en el capítulo segundo («El vino de cocos, una técnica viajera entre Filipinas y Nueva España») por el conocimiento que implicaba el trasvase de la planta y el papel desempeñado por el galeón de Manila como vehículo de transferencia cultural en ambos sentidos. Para producir vino de cocos se requerían unos saberes tecnológicos que los pobladores de la costa pacífica del virreinato novohispano adoptaron de los naturales filipinos que arribaban en el galeón como servidores del navío. Para reconstruir la tecnología mexicana, desaparecida ya en el siglo XVIII y substituida por la del mexcal, la autora hubo de acudir en primer lugar a la evidencia que le proporcionó su trabajo de campo sobre las áreas donde aún se manufactura en las islas Filipinas. Allí pudo ser testigo del proceso de extracción, fermentación y destilación necesarios para conseguir este aguardiente de elevada graduación. Con ello, la autora comprobó la existencia de grandes analogías entre la cultura de las bebidas filipina (actual) y mexicana (histórica), y que completó a partir de señaladas fuentes históricas que guardan los archivos locales citados más arriba. Identifica y estudia además los dos mayores centros de elaboración en México: determinadas haciendas ubicadas las unas en el área de Colima-Motines y las otras en la de Acapulco-Zacatula, más al sur. Finaliza el segundo capítulo con la evidencia del gran cambio experimentado en el paisaje natural, durante el siglo XVII, que supuso la substitución del cacahuanantzin, el árbol que proporcionaba sombra a la delicada planta del cacao — que sostenía la producción local—, por la palma de coco y que resultó clave para la economía de ambas áreas, una asociación que tuvo su réplica a su vez en las islas Filipinas donde aún se mantiene. Pero destaca también 
la autora cómo la difusión de las dos nuevas bebidas (la tuba fermentada y el aguardiente o vino de cocos destilado) competirían ventajosamente durante toda la centuria en los mercados urbanos y mineros con los «vinos de la tierra» e incluso los llamados de Castilla.

La segunda parte de la publicación («Sabedores y aprendices») se abre en un tercer capítulo en donde precisa los orígenes y la integración en la costa pacífica de estos «sabedores», los llamados «indios chinos», experimentados en la elaboración del nuevo producto. La denominación de indios chinos ya se empleaba en las fuentes filipinas del siglo XVI para diferenciarlos de los entonces calificados como «indios nuestros», esto es, los del continente americano. Muchos de los que viajaban como servidores del galeón de Manila no realizaron nunca el viaje de retorno a las islas, algo que pretendían controlar las autoridades de Acapulco pero que nunca pudieron conseguir, hasta tal punto que aún en la actualidad existen poblaciones en el entorno de su puerto conformadas por descendientes de aquellos indios chinos. Muchos se habrían desplazado hacia el norte hasta alcanzar los actuales estados de Michoacán, Colima y Jalisco. Traían todos ellos unos conocimientos y saberes tradicionales de los lugares de donde procedían — de las islas Filipinas, pero también del resto del sudeste asiático-, lo que les permitió una fácil y rápida integración en las haciendas de palma de las áreas de destino, algo que la autora reconstruye a partir de un buen número de historias de vida. En el capítulo cuarto se estudian las transformaciones derivadas de la introducción del vino de cocos en las pautas de consumo y producción de los pueblos de indios. Para épocas prehispánicas y durante la primera centuria de dominio europeo, no existen evidencias del empleo de aguardientes destilados sino que los pueblos originarios optaron únicamente por bebidas fermentadas no superiores a los 12 grados de volumen alcohólico, las únicas conocidas. Sin embargo, la incorporación de los indios chinos facilitó la introducción de destilados cuya graduación podía superar los 50 grados. El mecanismo más común de comercialización del nuevo producto entre los pueblos de indios era el del repartimiento forzoso de mercancías - aunque se vendía también directamente de forma clandestina-, mediante el cual los mercaderes españoles la despachaban a los alcaldes mayores e intermediarios indígenas. El consumo del vino de cocos se extendió de tal forma que resultó insuficiente para satisfacer la demanda, de modo que los propios campesinos indígenas hubieron de entrar en el ámbito de la producción adquiriendo de los indios chinos los saberes necesarios para ello. Al tiempo, la práctica de elaboración del aguardiente se extendió con la incorporación de otras materias primas, como el maguey del que se extrajeron los primeros mezcales.

Se inicia la tercera y última parte del libro («Productores, consumidores y castigadores») con un capítulo quinto en el que se estudia la evolución de la producción del vino de cocos en los núcleos mencionados de Colima-Motines y Acapulco-Zacatula, los de mayor concentración de haciendas cocoteras. Entramos así de lleno en el campo de la historia económica. La introducción del aguardiente de cocos coincidió en el tiempo con el reforzamiento por parte de las autoridades virreinales de disposiciones prohibicionistas para la prevención de la embriaguez y el deterioro de la moral pública. No obstante 
las proscripciones, durante el periodo de 1600-1627 la producción se extendió sin contrariedades por todo el litoral pacífico. Para el cálculo de las dimensiones del crecimiento y en ausencia de cifras agregadas, la autora fundamenta su investigación en base a la contabilidad de un grupo de haciendas pautadoras que completa con referencias procedentes de inventarios de bienes y otro tipo de informaciones puntuales. El periodo 16281670 se distinguió por el supresión de las prohibiciones virreinales sobre fabricación y distribución, de lo que derivó un alza aún mayor del volumen de producción, apoyada en este caso en la evidencia de cifras oficiales, con un pico notable en 1631. No obstante, el periodo posterior de 1671-1700 destacó por una reducción en el volumen de producto, como manifiestan la desaparición de todo tipo fuentes alusivas y la deslocalización de las haciendas litorales hacia el interior. La reconstrucción de las series de diezmos confirman esta crisis, que queda acreditada durante el periodo de 1700 a 1724. A estas alturas se promulgó una nueva política prohibicionista, que coincidió además - y esto resulta bien significativo- con la difusión de nuevas bebidas alcohólicas elaboradas con inputs de menor coste, como el maguey, cuya extracción no dependía de conocimientos especializados, su manufactura resultaba menos compleja y sus suelos no precisaban de características especiales como las que necesitaba el aguardiente de cocos y que permitieron en conjunto una mayor versatilidad entre oferta y demanda.

La autora destina el capítulo quinto a estudiar y cuantificar la comercialización del producto en las principales ciudades y poblaciones mineras durante el siglo XVII, para lo que emplea la visitada fuente de los libros de alcabalas. El procedente del binomio Colima-Motines alcanzaba mercados de larga distancia y se concentraba en dos áreas: de una parte, la del obispado de Michoacán (San Luis Potosí, Valladolid, Zamora, entre otras ciudades), el Bajío y la Ciudad de México y su entorno (Guanajuato, León, Querétaro, Toluca, etc.). De otra, la Nueva Galicia (Aguascalientes, Guadalajara, Zacatecas) y los centros mineros del norte (Durango, Sombrerete y otros), donde constituía una bebida estimulante para el trabajo intensivo de los trabajadores de las minas. El segundo núcleo de importancia en la producción de la bebida, el binomio Zacatula-Acapulco, de menor magnitud y escasamente conocido, destinaba la mercancía en gran medida al mercado local y solo excepcionalmente a Ciudad de México y a las ciudades y poblados mineros del obispado de Michoacán.

Remata, finalmente, la investigación con un epílogo en el que la autora recupera la polémica, abierta hace ya algunas décadas pero aún irresuelta, sobre los orígenes del actual aguardiente de maguey, el mezcal, una bebida de elevada graduación que muchos mexicanos consideran uno de los elementos simbólicos que definen su identidad (en realidad, el afamado tequila no constituye más que una variedad de mezcal). Para algunos estudiosos, la bebida procedería de la época prehispánica y aportan para ello la información que proporcionan determinadas ruinas de hornos de elaboración descubiertos en el noroeste mexicano, lo que alteraría nuestros conocimientos sobre el consumo de aguardientes, descubiertos en Europa durante el siglo XVI. Sin embargo, la hipótesis quedó refutada al observarse que la tecnología para su obtención era de procedencia asiática o arábiga (Bruman), una argumentación que resultó revalidada desde perspectivas etnobo- 
tánicas y etnohistóricas (Zizumbo, Colunga). Por ello y pese a ciertas contrarréplicas, la evidencia empírica corrobora únicamente la presencia de hornos de fermentación, pero nunca de destilación, las dos secuencias obligadas para conseguir el licor, por lo que el relato histórico lo confirma, según la autora, como un producto novohispano descartando su origen entre los pueblos prehispánicos. Pero a esta polémica se adhiere una segun$\mathrm{da}$, la de considerar al mezcal como el heredero del aguardiente o vino de cocos. A favor de esta argumentación, la autora aporta el testimonio del uso de la tecnología asiática (filipina) entre los mexicanos, aunque habría experimentado determinadas modificaciones a tenor de las necesidades locales, en especial la sustitución de la materia prima (el maguey por el coco, que aportaba una mayor flexibilidad y ahorro de costes, como vimos) y la evolución de la propia tecnología (introducción del alambique arábigo de cobre y abandono del tradicional).

En resumen, el libro de Paulina Machuca supone una notable aportación a la historia de la alimentación en su conjunto, encaja en los estudios existentes sobre la historia de la alimentación en Europa, y explica específicamente su evolución en el continente americano.

Luis Alonso Alvarez Universidade de A Coruña

(A Coruña, España) 